\title{
Individual variation in the erythropoietic response to altitude training in elite junior swimmers
}

\author{
B Friedmann, F Frese, E Menold, F Kauper, J Jost, P Bärtsch
}

Br J Sports Med 2005;39:148-153. doi: 10.1136/bjsm.2003.011387

See end of article for authors' affiliations

Correspondence to: Dr Birgit Friedmann, Department of Sports Medicine, Medical Clinic and Policlinic, University of Heidelberg, Im

Neuenheimer Feld 710,

69120 Heidelberg,

Germany;

birgit friedmann@med.

uni-heidelberg.de

Accepted 4 May 2004
Objectives: Inter-individual variations in sea level performance after altitude training have been attributed, at least in part, to an inter-individual variability in hypoxia induced erythropoiesis. The aim of the present study was to examine whether the variability in the increase in total haemoglobin mass after training at moderate altitude could be predicted by the erythropoietin response after $4 \mathrm{~h}$ exposure to normobaric hypoxia at an ambient $\mathrm{Po}_{2}$ corresponding to the training altitude.

Methods: Erythropoietin levels were measured in 16 elite junior swimmers before and after $4 \mathrm{~h}$ exposure to normobaric hypoxia $\left(\mathrm{Fio}_{2} 0.15, \sim 2500 \mathrm{~m}\right.$ ) as well as repeatedly during 3 week altitude training $(2100-2300 \mathrm{~m})$. Before and after the altitude training, total haemoglobin mass (CO rebreathing) and performance in a stepwise increasing swimming test were determined.

Results: The erythropoietin increase (10-185\%) after $4 \mathrm{~h}$ exposure to normobaric hypoxia showed considerable inter-individual variation and was significantly $(p<0.001)$ correlated with the acute erythropoietin increase during altitude training but not with the change in total haemoglobin mass (significant increase of $\sim 6 \%$ on average). The change in sea level performance after altitude training was not related to the change in total haemoglobin mass.

Conclusions: The results of the present prospective study confirmed the wide inter-individual variability in erythropoietic response to altitude training in elite athletes. However, their erythropoietin response to acute altitude exposure might not identify those athletes who respond to altitude training with an increase in total haemoglobin mass.
$\mathrm{T}$ here is remarkable inter-individual variability in improvement in sea level performance after training at moderate altitudes of 2000-2500 m. Chapman et al presumed that this variability might largely be explained by individual variation in the erythropoietic response to altitude. In a retrospective analysis of a controlled study, they showed that college runners who had responded to altitude training with significant improvement in a $5000 \mathrm{~m}$ run at sea level, experienced a distinctly increased erythropoiesis during 4 weeks of altitude raining. Compared to other college runners who had not improved after altitude training, these athletes displayed a larger acute increase in erythropoietin (EPO), still had significantly elevated EPO levels after 14 days of altitude training, and experienced significant augmentation of total red cell volume after return to sea level. It was concluded that a large acute increase in EPO, sufficient to cause an increase total red cell volume, is an important determinant for improvement in sea level performance after altitude training.

Great inter-individual variability has been found in the erythropoietic response to high and moderate altitudes. ${ }^{23}$ During a 3 week sojourn at high altitude $(6542 \mathrm{~m})$ the increase in EPO and the subsequent haemoglobin response to EPO were both found to vary considerably. ${ }^{2}$ More recently, Ge et $a l^{3}$ reported a marked individual variability in EPO increase after 6 and $24 \mathrm{~h}$ exposure to hypobaric hypoxia equivalent to altitudes of 1780-2800 m. Furthermore, they concluded that altitudes $\geqslant 2100-2500 \mathrm{~m}$ might be a threshold for the induction of increased erythropoiesis in most athletes.

In the present prospective study, we investigated whether the EPO response to acute exposure to normobaric hypoxia allows the identification of athletes who will respond to altitude training with a distinct increase in EPO concentration and a subsequent augmentation of haemoglobin mass. We hypothesised that the EPO response after $4 \mathrm{~h}$ exposure to normobaric hypoxia at an ambient $\mathrm{Po}_{2}$ similar to the training altitude is indicative for the extent of acute EPO increase during a training camp at moderate altitude and that a large EPO increase after acute hypoxic exposure is associated with a large increase in total haemoglobin mass after training at moderate altitude and vice versa.

To test our hypotheses, EPO was measured in 16 elite junior swimmers (nine males and seven females) prior to and after $4 \mathrm{~h}$ exposure to normobaric hypoxia $\left(\mathrm{Fio}_{2} \mathrm{0.15}\right)$ as well as repeatedly during living and training at an altitude of 2100-2300 m. Furthermore, total haemoglobin mass was determined with $\mathrm{CO}$ rebreathing before and after altitude training as was performance in an incremental swimming test.

\section{METHODS \\ Subjects}

A total of 20 elite junior swimmers (11 females and nine males) volunteered for the study. Four swimmers (two females and two males) suffered from infectious diseases during altitude training or the testing period and had to reduce or even stop their training for several days. Their data were not included. The descriptive data of the remaining 16 swimmers were: 16.4 (standard deviation (SD) 1.4) years, $180.3(8.5) \mathrm{cm}, 70.4(9.5) \mathrm{kg}$; females $(\mathrm{n}=9): 15.4(0.9)$ years, $174.0(4.7) \mathrm{cm}, 63.7(4.3) \mathrm{kg}$; males $(\mathrm{n}=7)$ : $17.7(0.8)$ years, $188.3(4.2) \mathrm{cm}, 79.0(6.7) \mathrm{kg}$. All swimmers had been intensively training for at least 5 years and most of them had successfully participated in European or World Championships or in European Junior Championships. Written informed consent was obtained in each case and

Abbreviations: EPO, erythropoietin; $\mathrm{Hb}$, haemoglobin concentration; $\mathrm{Hct}$, haematocrit; MCV, mean corpuscular erythrocyte volume; RBV, red blood cell volume; THM, total haemoglobin mass 
also from their parents for those athletes younger than 18 years. The study was approved by the Ethics Committee of the Medical Faculty of the University of Heidelberg, Germany. Six of the female and three of the male swimmers had already participated in between one and four training camps at moderate altitudes of 1800-2300 m; none had been to altitude for at least 6 months prior to the study.

None of the swimmers was anaemic (females: haemoglobin concentration $(\mathrm{Hb})>11.7 \mathrm{~g} \mathrm{dl}^{-1}$, males $\mathrm{Hb}>13.5 \mathrm{~g} \mathrm{dl}^{-1}$, normal values for haematocrit (Hct) and mean corpuscular erythrocyte volume (MCV)). Ferritin values (females: 33.2 (SD 13.6) $\mu \mathrm{g} \mathrm{l}^{-1}$, males: 50.7 (27.4) $\mu \mathrm{g} \mathrm{l}^{-1}$ ) were within normal range except for two females whose ferritin values were $<25 \mathrm{\mu g} \mathrm{l}^{-1}$. They were treated with $567.7 \mathrm{mg}$ ferrousglycin-sulfate (gelatin coated capsules) equivalent to $100 \mathrm{mg}$ elemental iron daily throughout the study.

\section{Experimental protocol}

Tests before altitude training

A total of 10 athletes (five females, five males) were tested 2 weeks, and six athletes (four females, two males) 1 week before travelling to the altitude training camp as follows:

- Day 1: Health checks including blood draws (to determine $\mathrm{Hb}, \mathrm{Hct}$, and ferritin) and incremental cycle spiroergometry in normoxia.

- Day 2: Incremental swimming test.

- Day 3: Venous blood draws in the morning to determine baseline EPO; $4 \mathrm{~h}$ in normobaric hypoxia $\left(\mathrm{Fio}_{2} \mathrm{0.15}\right)$; blood draws to determine EPO response to acute altitude exposure; and measurement of total haemoglobin mass with CO rebreathing.

\section{Tests after altitude training}

All swimmers performed the incremental swimming test and their total haemoglobin mass, Hb, and Hct were measured 10 days after return to sea level, the time when athletes and coaches consider that maximal sea level performance is achieved after altitude training.

\section{EPO measurements during altitude training}

Blood draws were conducted in the mornings of days 1, 2, 8, and 20 of altitude training. As the swimmers did not travel together and had arrived at the altitude training camp in three groups at different times of the day, the acute EPO response during altitude training was determined as the maximal individual value of measurements taken on days 1 and 2 at altitude. On average, maximal EPO increases were determined after 22.3 (SD 11.9) h at moderate altitude.

\section{Blood analyses}

Blood samples $(5 \mathrm{ml}$ ) were drawn into an EDTA tube from an antecubital vein in the sitting position. Hb, erythrocyte count, and MCV were measured with a Coulter T 840 Counter (Coulter Electronics, Krefeld, Germany). Hct was determined with microcentrifugation. For determination of serum EPO, $7 \mathrm{ml}$ of venous blood were drawn from an antecubital vein, centrifuged $\left(3000 \mathrm{rpm}, 10 \mathrm{~min}, 4^{\circ} \mathrm{C}\right)$ within $30 \mathrm{~min}$, and stored at $-20^{\circ} \mathrm{C}$ until measurement (Erythropoietin ELISA, IBL, Hamburg, Germany). Ferritin was measured photometrically (EIAgen Ferritin Kit, Adaltis, Freiburg, Germany) before altitude training. Each measurement was carried out in duplicate.

\section{Measurement of total haemoglobin mass}

Total haemoglobin mass was measured with carbon monoxide (CO) using a rebreathing method as described previously. ${ }^{4}$ The athlete ventilated a mixture of CO $(0.85 \mathrm{ml}$
$\mathrm{CO}$ per kg body weight) in $5 \mathrm{l}$ of $\mathrm{O}_{2}$ in a closed system. If necessary, $\mathrm{O}_{2}$ was refilled. Immediately before starting the measurement, $5 \mathrm{ml}$ of venous blood were drawn from an antecubital vein for determination of $\mathrm{Hb}$, Hct, erythrocyte count, and MCV. The COHb fraction was measured in venous blood from an antecubital vein with an automated system (270 CO-Oxymeter, CIBA-Corning, Fernwald, Germany) before and every 2 min while ventilating this mixture until a plateau was reached, usually near $5 \%$ COHb after 10 $15 \mathrm{~min}$. Total haemoglobin mass (THM) was calculated as:

THM = K MCO (100/DCOHB 1.34).

Red blood cell volume (RBV) was calculated as

$\mathrm{RBV}=\mathrm{THM} / \mathrm{MCHC}$

according to Burge et $\mathrm{al}^{5}$, where $\mathrm{K}$ is barometric pressure/[760 $(1+(0.003669$ temperature $))]$, MCO is volume of added CO in $\mathrm{ml}$, and DCOHB is the difference between basal COHb and maximal COHb multiplied by 1.34 as $1.34 \mathrm{ml} \mathrm{CO}$ bind to $1 \mathrm{~g}$ $\mathrm{Hb}$.

\section{Exercise testing}

The incremental swimming tests consist of five steps starting at an intensity of about $80 \%$ of the personal best performance at the time of testing. Intensity is increased by $5 \%$ per step until maximal performance is reached in the last step. Step duration (100-400 m) and swim style depend on the swimmer's specialisation. These tests were conducted in a $50 \mathrm{~m}$ pool and are regularly performed by elite German swimmers to monitor performance and derive training recommendations. For lactate measurement, $20 \mu \mathrm{l}$ of capillary blood were drawn from the earlobe at the end of each step and repeatedly after the maximal step and measured using an automated system (EBIO plus, Eppendorf, Hamburg, Germany).

\section{Normobaric hypoxia}

The swimmers were exposed to normobaric hypoxia by diluting ambient air with nitrogen in a special room. The $\mathrm{N}_{2}$ enriched air supply is controlled by an $\mathrm{O}_{2}$ sensor driven inlet valve; $\mathrm{N}_{2}$ enrichment is achieved by an $\mathrm{O}_{2}$ separation system using compression (AGA, Hamburg, Germany). In the present study the ambient inspiratory oxygen fraction $\left(\mathrm{Fio}_{2}\right)$ was 0.15 simulating a degree of hypoxia corresponding to an altitude of about $2500 \mathrm{~m}$. Ambient $\mathrm{O}_{2}$ and $\mathrm{CO}_{2}$ were continuously monitored.

All tests in normoxia were conducted at a natural altitude of about $120 \mathrm{~m}$.

\section{Altitude training}

The altitude training camp took place in Monachil (Sierra Nevada), Spain, where the swimmers lived and trained at an altitude of $2100-2300 \mathrm{~m}$. The athletes performed $60-70 \mathrm{~km}$ of swim training per week, mainly endurance training with intensities below a lactate level of $4 \mathrm{mmol}^{-1}(55 \%)$ but with some lactate levels between 4 and $6 \mathrm{mmol} \mathrm{l}^{-1}(9 \%)$. About $30 \%$ of the training concentrated on improving swimming style. Training was supervised by experienced coaches. Lactate was measured in capillary blood during several training sessions and training intensity adjusted if necessary.

\section{Statistics}

Statistical analysis was performed with the software programs Sigmastat 2.0 and Sigmaplot 7.0 for Windows from Jandel Scientific (San Rafael, CA). Data are presented as mean (SD) values. Differences between values obtained before and after training and between measurements in normoxia and normobaric hypoxia were analysed using Student's paired $t$ test checking for normal distributions. For comparison of the EPO measurements over time, repeated measures ANOVA on Ranks was used followed by 
Dunnett's test for multiple comparison procedure to determine the source of difference. Correlations between selected parameters were analysed by linear regression. The level of significance was set at $\mathrm{p}<0.05$.

\section{RESULTS}

\section{Erythropoietin response}

EPO was significantly increased after $4 \mathrm{~h}$ exposure to normobaric hypoxia by $58.3 \%$ (SD $41.4 \%$ ) and on days 1 and 2 of altitude training by $51.8 \%(45.6 \%)(15.2(5.0)$ and $14.7(6.0) v 10.2(4.0) \mathrm{mU} \mathrm{ml}^{-1}$, respectively). On days 8 and 20 of altitude training, EPO was not significantly different from the values measured in normoxia (sea level baseline). There was a large individual variation in the EPO response after $4 \mathrm{~h}$ in normobaric hypoxia as well as during altitude training as shown in fig lA. The EPO increase after $4 \mathrm{~h}$ exposure to normobaric hypoxia was significantly correlated with the acute EPO increase during altitude training (fig 1B).

\section{Total haemoglobin mass and haemoglobin}

The changes in total haemoglobin mass showed a wide interindividual variability as can be seen in fig 2A. After 3 weeks of altitude training, total haemoglobin mass was significantly increased by $6 \%$ on average, from 855 (SD 185) to 909 (196) g (12.1 (1.6) to 12.9 (1.8) $\mathrm{g} \mathrm{kg}^{-1}$ body weight; RBV: 35.1 (4.2) to 36.9 (5.1) $\mathrm{ml} \mathrm{kg}^{-1}$ body weight). However, there were no significant correlations between the acute EPO increase at altitude and the change in total haemoglobin mass (fig 2B) or between EPO on days $8(r=-0.08, \mathrm{p}=0.78)$ and $20(r=0.04, \mathrm{p}=0.89)$ of altitude training and changes in total haemoglobin mass (both parameters expressed as per cent sea level baseline).

Neither Hb nor Hct had changed significantly after altitude training (females: $\mathrm{Hb} 13.3$ (SD 0.6) $\mathrm{g} \mathrm{dl}^{-1}$ after training $v$ $13.0(0.8) \mathrm{g} \mathrm{dl}^{-1}$ before training, Hct $39.9 \%(2.2 \%) \vee 39.5 \%$ (2.5\%); males: Hb $14.8(0.3) \mathrm{g} \mathrm{dl}^{-1} v 15.1$ (0.4) $\mathrm{g} \mathrm{dl}^{-1}$, Hct $44.1 \%(1.2 \%) \vee 45.4 \%(1.4 \%)$.

\section{Performance in the incremental swimming test}

Considerable individual variation was found in the improvement in maximal and submaximal performance as demonstrated in fig 3A and B. Maximal performance and performance at $4 \mathrm{mmol} \mathrm{l}^{-1}$ lactate concentration were significantly increased by about $2-3 \%$ after altitude training.
Maximal lactate concentration remained unchanged (10.3 (SD 3.0) $\mathrm{mmol} \mathrm{l}^{-1}$ after $v 9.6$ (3.0) $\mathrm{mmol} \mathrm{l}^{-1}$ before altitude training). There were no significant correlations between the change in total haemoglobin mass and the change in maximal performance nor between the change in total haemoglobin mass and the change in performance at a $4 \mathrm{mmol} \mathrm{l}^{-1}$ lactate concentration.

\section{DISCUSSION}

The main new observation of the present study was a significant correlation between the EPO increase that occurred during the first days of living and training at moderate altitude and the EPO response after $4 \mathrm{~h}$ exposure to normobaric hypoxia at an ambient $\mathrm{Po}_{2}$ similar to the training altitude. However, the increase in total haemoglobin mass after altitude training was correlated neither with the acute EPO increase nor with the EPO values measured in the middle and at the end of 3 week altitude training. These results indicate that athletes who respond to training at moderate altitude with a large acute EPO increase might be identified with the help of short exposure to equivalent normobaric hypoxia; however, apparently, high acute EPO increases upon altitude exposure did not always yield large increases in total haemoglobin mass after living and training at moderate altitude.

Elite athletes from various sports train at moderate altitude (1700-3000 m) in an attempt to improve their aerobic capacity because of a hypoxia induced increase in total haemoglobin mass. ${ }^{67}$ Results of studies on the effects either of living and training at moderate altitude or of living at moderate altitude and training at low altitude on total haemoglobin mass (red cell volume) and sea level performance are controversial. ${ }^{8-16}$ In most of the studies with elite athletes, total haemoglobin mass was not significantly increased after living and training at moderate altitude. $^{10-1215} 16$

Several explanations for the unexpected lack of increase in total haemoglobin mass after altitude training have been suggested: insufficient iron stores could have prevented efficient erythropoiesis ${ }^{17}$; altitudes $<2100-2500 \mathrm{~m}$ seem to be below the threshold for efficient hypoxia induced EPO release $^{18}$; polycythaemic hypervolaemia caused by years of endurance training in elite athletes might have reached a maximum with no potential for a further increase ${ }^{12}$ and substantial individual variation in the erythropoietic response
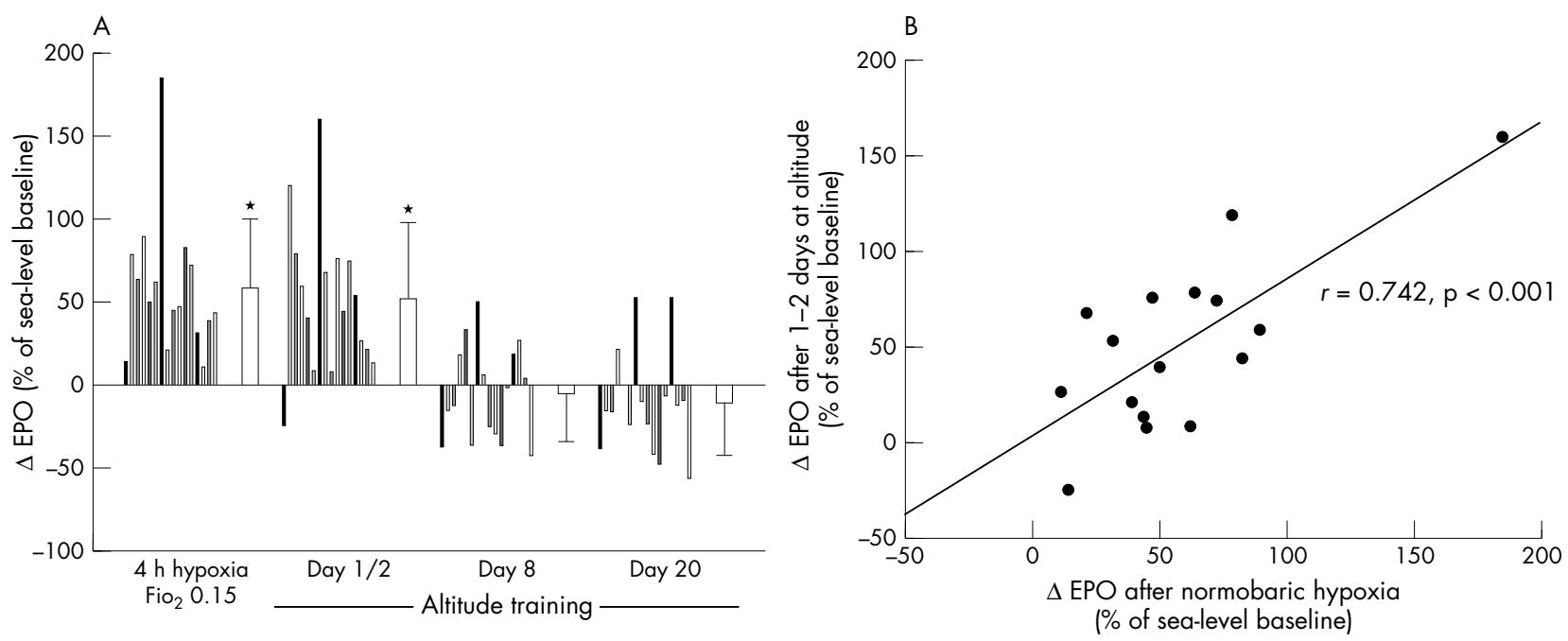

Figure 1 (A) Changes in EPO after $4 \mathrm{~h}$ exposure to normobaric hypoxia $\left(\mathrm{Fio}_{2} \mathrm{O}_{\mathrm{15}}\right)$ and during altitude training. The data are presented as per cent differences to sea level baseline values. Individual values and mean and standard deviation values are shown. *Indicates significantly different from sea level baseline. (B) Correlation between the EPO response to $4 \mathrm{~h}$ exposure to normobaric hypoxia $\left(\mathrm{FiO}_{2} \mathrm{O}(15)\right.$ and the acute EPO response during training at an altitude of $2100-2300 \mathrm{~m}$. The data are presented as per cent sea level baseline values. 

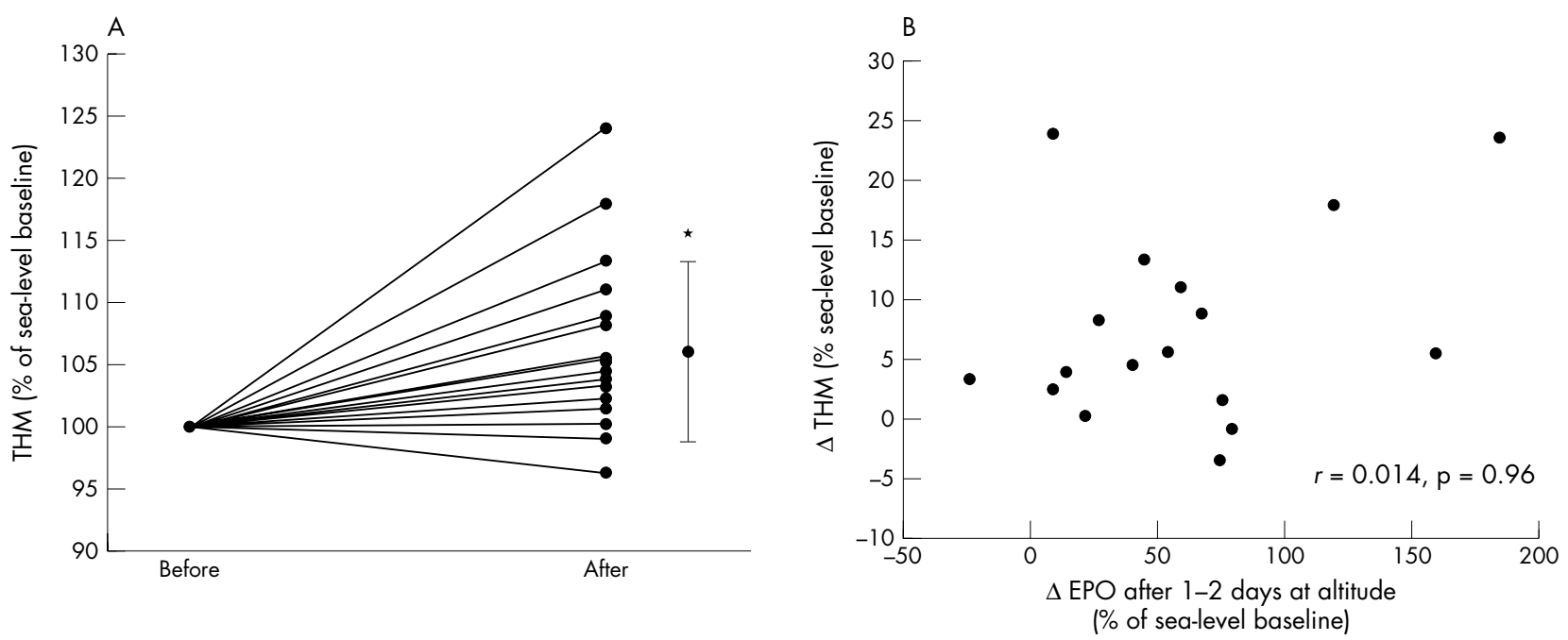

Figure 2 (A) Changes in THM after altitude training. The data are presented as per cent sea level baseline values. Individual values and mean and standard deviation values are shown. *Indicates significantly different from sea level baseline $(p<0.001)$. (B) Correlation between the acute EPO response during altitude training and the change in THM after altitude training. The data are presented as per cent differences from sea level baseline values.

to altitude might have been responsible for the lack of significant changes and might also explain the considerable inter-individual variation in sea level performance after altitude training. ${ }^{1}$ The present study focused on the question of whether the EPO response to acute normobaric hypoxia might indicate which athletes would improve their sea level performance after training at moderate altitude because of a hypoxia induced increase in total haemoglobin mass. We did not include a control group of elite junior swimmers performing equivalent training at sea level as it was not the aim of this study to examine whether or not the mean increase in sea level performance is greater after altitude training compared to equivalent sea level training.

There is some debate about the physiological limit of total haemoglobin mass in endurance athletes. While Gore et al ${ }^{12}$ suggested that world class endurance athletes might have "maximised" their total haemoglobin mass after many years of sea level training, Schmidt et al ${ }^{19}$ recently reported significantly higher total haemoglobin mass in professional cyclists living at an altitude of $2600 \mathrm{~m}$ compared to professional cyclists living at sea level with similar $\mathrm{Vo}_{2 \max }$, indicating that there is still potential for a further increase in total haemoglobin mass in sea level endurance athletes if they perform altitude training. The subjects in the present study were elite junior swimmers who undoubtedly still had the potential to increase total haemoglobin mass, whose erythropoiesis was not impaired by insufficient iron availability, and who lived and trained at an altitude high enough for a sufficient hypoxia induced increase in erythropoiesis. The significant mean increase in total haemoglobin mass (red cell volume) of $0.8 \mathrm{~g} \mathrm{~kg}^{-1}\left(1.8 \mathrm{ml} \mathrm{kg}{ }^{-1}\right)$ found in these elite junior swimmers after 3 weeks of living and training at moderate altitude is comparable to the results of Levine et $a l^{13}$ who reported a mean increase in red cell volume of $3.0 \mathrm{ml} \mathrm{kg}-1$ in college runners after 4 weeks of living and training at an altitude of $2500 \mathrm{~m}$. The individual variation in the changes of total haemoglobin mass in the present study was remarkable and varied between a $3.7 \%$ decrease and a $24 \%$ increase in the sea level baseline value (fig 2). There is also some debate about the extent to which total haemoglobin mass can be increased during altitude acclimatisation. Because of the results of a dose-response study in which the
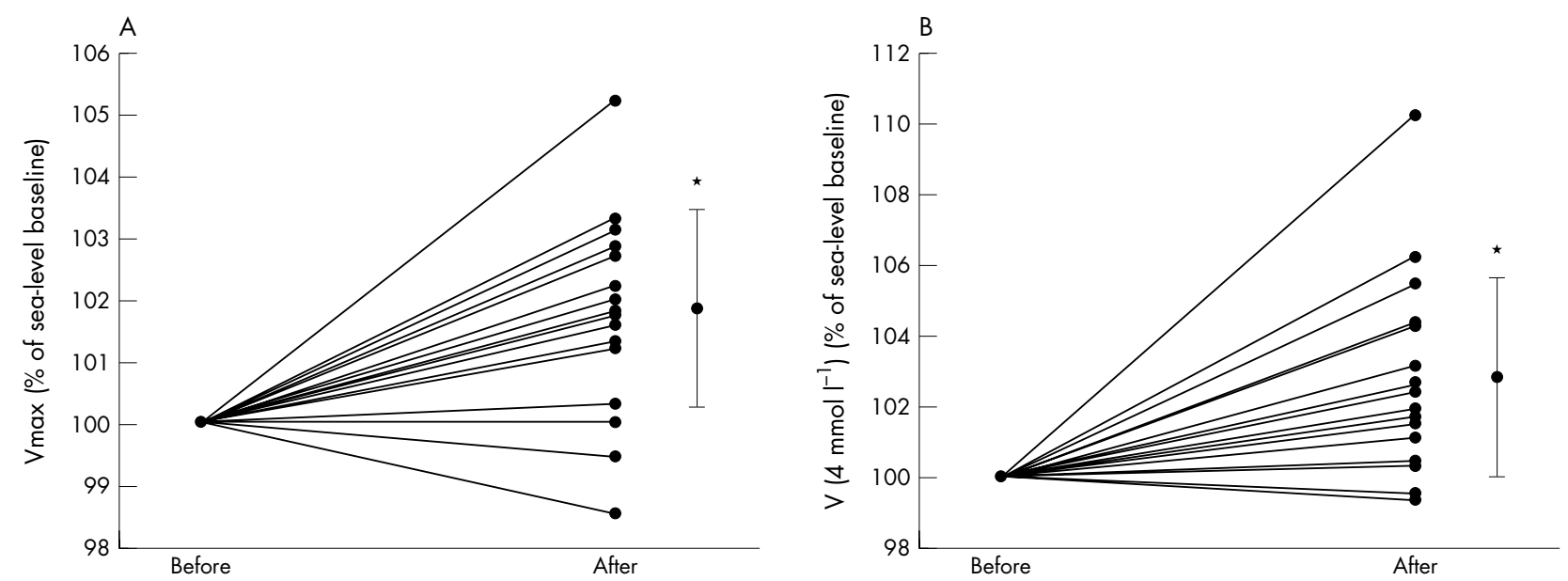

Figure 3 Changes in maximal performance and in performance at a $4 \mathrm{mmol} \mathrm{I}-1$ lactate concentration in an incremental swimming test. The data are presented as per cent sea level baseline values. Individual values and mean values and standard deviation are shown. *Indicates significantly different from sea level baseline $(p<0.001)$. $V$, velocity. 


\section{What is already known on this topic}

Wide inter-individual variations have been observed in the increase in erythropoietin levels during altitude exposure as well as in the increase in total haemoglobin mass and in the improvement in sea-level performance after altitude training.

changes in $\mathrm{Hb}$ during a 6 week treatment with recombinant human EPO were measured ${ }^{20}$ in healthy young males, the results of a number of altitude acclimation studies with large increases in red cell volume were questioned. ${ }^{21}$ According to the calculations of Sawka et $a^{21}$ and of Berglund and Ekblom, ${ }^{20}$ the $24 \%$ increase in total haemoglobin mass in one female swimmer in the present study seems to be incredibly high. However, to our knowledge, there exist no studies in which the changes in total haemoglobin mass following treatment with recombinant human EPO were measured and it is not known to what extent total haemoglobin mass can be increased in trained subjects when circulating EPO levels are elevated.

There was no significant correlation between the EPO response to altitude and the change in total haemoglobin mass. This finding is in accordance with results reported by Rusko et $a l^{14}$ who did not find a correlation between EPO values on days 2 and 25 of hypoxia exposure and the significant increase in total red cell volume in cross country skiers who lived $12-16$ h daily for 25 days in normobaric hypoxia $\left(\mathrm{Fio}_{2} \mathrm{0.15}\right)$ and who trained in normoxia. Thus, the assumption made by Chapman et al ${ }^{1}$ that a large acute EPO increase during altitude exposure would cause a respective increase in total haemoglobin mass could not be confirmed.

Apparently, there is no simple linear relationship between punctual EPO measurements during altitude training and the increase in total haemoglobin mass. One reason might be an inter-individual variation in the response to the hypoxia induced EPO increase. Richalet et a ${ }^{2}$ not only found a great inter-individual variability in the EPO response to high altitude at $6542 \mathrm{~m}$, but also reported high and low responders to the hypoxia induced EPO increase, with, for example, relatively low EPO levels in subjects with sharp $\mathrm{Hb}$ increases. Furthermore, the inter-individual variability in the EPO response to hypoxia is not clearly understood. It can partially be explained by variations in $\mathrm{O}_{2}$ supply to the EPO producing renal tissue, but renal blood flow and $\mathrm{O}_{2}$ consumption in the tubular cells seem to be even more important determinants. ${ }^{2} 3$ Renal tissue oxygenation, which is improved with acclimatisation, to a great extent explains the decrease in EPO during prolonged altitude exposure. ${ }^{2}{ }^{1422}$ As could be seen in the present study, the EPO decrease had occurred after about l week of exposure to moderate altitude when secondary polycythaemia has not yet completely developed. ${ }^{\circ}$

Another reason for the lack of significant correlation between the EPO response to altitude and the change in total haemoglobin mass could be a mild neocytolysis that might have occurred in some of the swimmers during the 10 days between return to sea level and measurement of total haemoglobin mass. Rice et $a^{23}$ observed a $7-10 \%$ decrease in red cell mass in polycythaemic high altitude $(4380 \mathrm{~m})$ residents with $\mathrm{Hb}$ values of $21-26 \mathrm{~g} \mathrm{dl}^{-1}$ on descent to sea level due to neocytolysis caused by suppressed EPO levels. Gore et $a l^{12}$ and Dill et al ${ }^{10}$ did not report a significant decrease in total haemoglobin mass in elite athletes during repeated measurements up to 20 days after training at moderate altitude (2300-2700 m). We cannot completely exclude that total haemoglobin mass slightly decreased in some of the swimmers during the first days after descent to sea level. However, we had decided to measure total haemoglobin mass
What this study adds

The erythropoietin response after $4 \mathrm{~h}$ hypoxic exposure at an ambient $\mathrm{PO}_{2}$ corresponding to the training altitude is closely related to the acute erythropoietin increase during altitude training but does not allow prediction of the variation in the increase in total haemoglobin mass or in sea-level performance after descent.

and performance 10 days after return to sea level because, according to the experienced German coaches, this time interval is required for swimmers to achieve maximal sea level performance after altitude training.

The importance of increased total haemoglobin mass for aerobic capacity has been shown repeatedly ${ }^{24} 25$ and is supported by studies on blood doping. ${ }^{26}$ Therefore, a wide inter-individual variability in sea level performance after altitude training might very likely be explained by the observed inter-individual variation in the change in total haemoglobin mass. In the present study, the changes in total haemoglobin mass did not correlate with the changes in maximal performance or with performance at a lactate concentration of $4 \mathrm{mmol} \mathrm{l}^{-1}$.

It is a weakness of the present study that we could not measure $\mathrm{Vo}_{2 \max }$ before and after altitude training in a specific test, for example during an incremental swim test in a flume. Instead, subjects performed an incremental swim test in a $50 \mathrm{~m}$ pool, the test performance at a $4 \mathrm{mmol} \mathrm{l}^{-1}$ lactate concentration being the most important measure. After altitude training, performance at a $4 \mathrm{mmol} \mathrm{l}^{-1}$ lactate concentration as well as maximal performance were significantly increased by $2-3 \%$. These increases showed considerable inter-individual variation which cannot be explained by differences in the individual training programs at altitude as the training of all swimmers was supervised by experienced coaches. Performance changes were not correlated with the change in total haemoglobin mass, perhaps because both aerobic and anaerobic capacity are very likely determining factors for maximal performance and for performance at a lactate concentration of $4 \mathrm{mmol} \mathrm{l}^{-1}$. It has been shown in other studies that anaerobic capacity can also be influenced by altitude training. ${ }^{27} 28$

In conclusion, this investigation confirmed the wide interindividual variation in the erythropoietic response to altitude training in elite athletes and demonstrated that the EPO increase which occurred during the first days of living and training at moderate altitude correlated well with the EPO response after $4 \mathrm{~h}$ exposure to equivalent normobaric hypoxia. However, the variability in the increase in total haemoglobin mass and in sea level performance after training at moderate altitude could not be predicted by the EPO response to acute hypoxic exposure.

\section{ACKNOWLEDGEMENTS}

The authors wish to thank all the swimmers and coaches, especially head coach Achim Jedamsky, for their co-operation. We further gratefully acknowledge the technical assistance of Judith Schönith and Martina Haselmayr throughout the study and the help of Stefan Borisch with the measurements of total haemoglobin mass.

\section{Authors' affiliations}

B Friedmann, F Frese, E Menold, F Kauper, P Bärtsch, Department of Sports Medicine, Medical Clinic and Policlinic, University of Heidelberg, Germany

J Jost, Olympic Training Centre Rhein-Neckar, Heidelberg, Germany

The study was supported by Deutscher Sportbund

Competing interests: none declared 


\section{REFERENCES}

1 Chapman RF, Stray-Gundersen J, Levine BD. Individual variation in response to altitude training. J Appl Physiol 1998;85:1448-56.

2 Richalet J-P, Souberbielle J-C, Antezana A-M, et al. Control of erythropoiesis in humans during prolonged exposure to the altitude of $6542 \mathrm{~m}$. Am J Physiol 1994;266:R756-64

3 Ge RL, Witkowski S, Zhang Y, et al. Determinants of erythropoietin release in response to short-term hypobaric hypoxia. J Appl Physiol 2002;92:2361-7

4 Friedmann B, Weller E, Mairbäurl $H$, et al. Effects of iron repletion on blood volume and performance capacity in young athletes. Med Sci Sports Exerc 2001:33:741-6.

5 Burge CM, Skinner S. Determination of haemoglobin mass and blood volume with CO: evaluation and application of a method. I Appl Physiol 1995;79:623-31.

6 Berglund B. High-altitude training. Aspects of haematological adaptation. Sports Med 1992;14:289-303.

7 Wolski LA, McKenzie DC, Wenger HA. Altitude training for improvements in sea level performance. Is there scientific evidence or benefit? Sports Med 1999;22:251-63.

8 Ashenden M, Gore CJ, Dobson GP, et al. "Live high, train low" does not change the total haemoglobin mass of male endurance athletes sleeping at a simulated altitude of $3000 \mathrm{~m}$ for 23 nights. Eur J Appl Physiol 1999;80:479-84.

9 Ashenden M, Gore CJ, Martin DT, et al. Effects of a 12-day "live high, train low" camp on reticulocyte production and haemoglobin mass in elite female road cyclists. Eur J Appl Physiol 1999;80:472-8.

10 Dill DB, Braithwaite K, Adams WC, et al. Blood volume of middle-distance runners: effect of $2300-\mathrm{m}$ altitude and comparison with non-athletes. Med Sci Sports Exerc 1974;6:1-7.

11 Friedmann B, Jost J, Rating T, et al. Effects of iron supplementation on total body haemoglobin during endurance training at moderate altitude. Int $I$ Sports Med 1999;20:78-85.

12 Gore CJ, Craig NP, Hahn A, et al. Altitude training at $2690 \mathrm{~m}$ does not increase total haemoglobin mass or sea level $\mathrm{VO}_{2}$ max in world champion track cyclists. J Sci Med Sport 1998;1:156-70.

13 Levine BD, Stray-Gundersen J. "Living high-training low": effect of moderatealtitude acclimatization with low-altitude training on performance. J Appl Physiol 1997;83:102-12

14 Rusko $\mathrm{H}$, Tikkanen $\mathrm{H}$, Paavolainen I, et al. Effect of living in hypoxia and training in normoxia on sea $\mathrm{VO}_{2}$ max and red cell mass. Med Sci Sports Exerc 1999;31:S86
15 Svedenhag J, Piehl-Aulin K, Skog C, et al. Increased left ventricular muscle mass after long-term altitude training in athletes. Acta Physiol Scand 1997; 161:63-70.

16 Telford RD, Graham KS, Sutton JR, et al. Medium altitude training and sealevel performance. Med Sci Sports Exerc 1996;28:S124.

17 Stray-Gundersen J, Alexander C, Hochstein A, et al. Failure of red cell volume to increase to altitude exposure in iron deficient runners. Med Sci Sports Exerc 1992;24:S90

18 Levine BD, Stray-Gundersen J. A practical approach to altitude training: where to live and train for optimal performance enhancement. Int J Sports Med 1992;13:S209-12.

19 Schmidt W, Heinicke K, Rojas J, et al. Blood volume and haemoglobin mass in endurance athletes from moderate altitude. Med Sci Sports Exerc 2002; $34: 1934-40$

20 Berglund B, Ekblom B. Effect of recombinant human erythropoietin treatment on blood pressure and some haematological parameters in healthy men. J Intern Med 1991;229:125-30.

21 Sawka MN, Convertino VA, Eichner ER, et al. Blood volume: importance and adaptations to exercise training, environmental stresses, and trauma/sickness. Med Sci Sports Exerc 2000;32:332-48.

22 Berglund B, Gennser M, Örnhagen H, et al. Erythropoietin concentrations during 10 days of normobaric hypoxia under controlled environmental circumstances. Acta Physiol Scand 2002;174:225-9.

23 Rice L, Ruiz W, Driscoll T, et al. Neocytolysis on descent from altitude: a newly recognized mechanism for the control of red cell mass. Ann Intern Med 2001;134:652-6.

24 Kanstrup I-L, Ekblom B. Blood volume and haemoglobin concentration as determinants of maximal aerobic power. Med Sci Sports Exerc 1984; 16:256-62.

25 Heinicke K, Wolfarth B, Winchenbach $\mathrm{P}$, et al. Blood volume and haemoglobin mass in elite athletes of different disciplines. Int J Sports Med 2001;22:504-12.

26 Celsing F, Svedenhag J, Pihlsted P, Ekblom B. Effects of anaemia and stepwise-induced polycythaemia on maximal aerobic power in individuals with high and low haemoglobin concentrations. Acta Physiol Scand 1987; 129:47-54.

27 Svedenhag J, Saltin B, Johansson C, et al. Aerobic and anaerobic exercise capacities of elite middle-distance runners after two weeks of training at moderate altitude. Scand J Med Sci Sports 1991;1:205-14.

28 Mizuno M, Juel C, Bro-Rasmussen TB, et al. Limb skeletal muscle adaptation in athletes after training at altitude. J Appl Physiol 1990;68:496-502. 